\title{
nature
}

\section{Promises and threats of the knowledge-based economy}

The need to place scientific knowledge at the heart of economic and social policy has underlined some of the limitations of focusing on trade liberalization. Developing countries should be a prime beneficiary.

S uddenly everyone is talking about it. For years, the idea that knowledge in general — and scientific knowledge in particular - plays a role in the global economy comparable to more tangible forms of resources and capital has been confined largely to the writing of left-leaning sociologists and policy analysts. As such, it has often been dismissed in political circles as little more than a woolly minded bid for extra funding from the scientific community and tax breaks on R\&D spending from industry. Over the past year, however, the concept that we live in an age when both the social and economic health of any society depends critically on its ability to harness scientific (and other) knowledge has gained wide political currency.

For some countries, of course, there is little new in the idea of using technical knowledge as a source of wealth and power. Those facing high labour costs (such as the United States) or a relative lack of natural resources (Sweden, Switzerland or Japan) have long realized that superior technical skill and innovation are their key to maintaining a competitive edge in the global market-place, and have sought to structure their industrial and social institutions around such insight. US economists such as Edwin Mansfield and Richard Nelson have identified the critical contribution made by technical innovation to economic growth; a recent analysis by 'knowledge management' expert Karl Sveiby suggests that half of the fastest-growing US companies are 'knowledge companies', selling the knowledge and skills of their employees rather than manufacturing products or providing services.

Elsewhere, for example in some of the major European economies, the message has taken more time to sink in. In the past, the prime role of scientific knowledge in the economy was portrayed as largely instrumental, leading to new products or reduced production costs. Only recently has the strategic value of intangible assets - such as scientific skills or intellectual property - come to be fully acknowledged. This was the key theme in the British white paper on competitiveness, published last month (see Nature 396, 714; 1998). It has also come fully to the fore in the European Union's fifth four-year Framework programme, due to be launched this year.

Conversely, part of the blame for the recent collapse of confidence in various Eastern economies is linked to their failure to establish a secure knowledge base for their economic 'miracles'. Proper information also oils the wheels of the market; when it is lacking, growth and investment can grind to a halt. But as acknowledgement of the significance of living in knowledge-based economies has spread, so too has experience of its drawbacks and limitations. Increased awareness of the potential economic value of scientific knowledge has led to growing reluctance to make such knowledge freely available throughout the research community. And the use of data banks to monitor the behaviour of individuals or market new products, both knowledgeintensive activities, has raised unprecedented questions about human privacy — including most recently those concerning an individual's genetic identity.

Last, but by no means least, as a recent report from the World Bank has pointed out, one of the most dangerous aspects of the global knowledge-based economy lies in the tensions created by the growing 'knowledge gap' between the knowledge-rich countries of the North and the (generally) knowledge-poor countries of the South (see Nature 395, 529; 1998). Wealth creates the ability to create the knowledge that can be used to create further wealth. But, without adequate means to distribute the benefits accruing from such knowledge, social disparities, and the jealousies they invoke, will only increase.

The key lies in combining commitment to two concepts that are far easier to define than to achieve: scientific excellence and social equity. The first requires continual vigilance and, occasionally, hard choices; without these, there is a tendency (as with currencies) for the mediocre to drive out the good. It is no longer sufficient to justify a research programme purely in terms of a generalized commitment to human welfare, just as a country (or a company) cannot guarantee itself economic success by leaping on the latest technological bandwagon. In each case, whether one is talking of scientific results or technological products, the combined effects of modern communications and trade liberalization mean that the closer these meet specific needs and global standards of quality (and cost-effectiveness), the greater benefit they are likely to generate.

But this does not mean that an untrammelled free market in the spread and application of scientific ideas is the most effective basis on which the knowledge economies of the future will be built. Governments may no longer have a role in picking technological winners, but they still have an essential task in both providing a sound underpinning for efforts to generate and exploit knowledge opportunities and compensating for market weaknesses and failures. Part of this responsibility lies in ensuring that moves to address needs not directly catered for by the market economy are nevertheless placed as firmly on a healthy scientific footing as are wealth-generating activities.

There have recently been encouraging signs that this message, too, is getting through to policy-makers, particularly in the context of aid to poorer nations. As shown in a series of articles in this issue by Nature correspondents around the world, the limitations of aid strategies that focus on providing external technical assistance or altering purely economic mechanisms are becoming widely recognized (see page 6). The key to successful aid is to find ways of enabling poorer countries to make their own way in the global knowledge economy - and of removing obstacles while at the same time harnessing knowledgegenerating capacities to the countries' social needs. This has been made both simpler and more urgent by the arrival of the Internet.

Devising strategies to achieve both objectives is likely to dominate the agenda of the World Conference on Science, to be held in Budapest at the end of the June, jointly organized by the United Nations Educational, Scientific and Cultural Organization and the International Council for Science. To accompany the preparatory discussions, Nature is dedicating part of its website (www.nature.com) over the next six months to detailed coverage of and comment on the challenge ahead. We encourage readers to participate in the debate. A constructive outcome would be a fitting way to greet the new millennium. 